\title{
MANAGEMENTS' ROLE IN DEVELOPMENT OF INFORMATION SYSTEM
}

\author{
GLIGORA MARKOVIC, M[aja]; POGARCIC, I[van] \& SUMAN, S[abrina]
}

\begin{abstract}
The business system is an entity of mutually connected economic, technical and social elements that produces goods or services for market needs. In the process, it uses the proper resources and bears the risk due to gaining the profit and other economic and social goals. The business processes, more or less, influence the inner and external environment since they provide answers to questions, such as, who, what, how, for whom and with what success accomplish his goals. The inner environment includes all factors submissive to the company. External environment cannot be controlled by company and it includes national laws and regulations, offer-demand relationship on the market, inflation, demographic changes, education and technological progress which combined represent a general or social environment that should be observed and reacted to
\end{abstract}

\section{INTRODUCTION}

The goal of business system is primarily economic, that is, gaining the profit and ensuring development and survival on the market. To be able to achieve these goals, business system requires external prerequisites, such as market needs and availability of needed resources, in line with inner prerequisites, such as: object of business, required assets, the available personnel, business tasks, size and location.

Managing the business can be ensured through decision making. If decisions are to be made meaningful, they shouldn't be made random. Conscious generating and processing of all information and their analysis due to realisation of set goals are the main reasons for planning the investments in new, or upgrading and modifying the existing information system which is essential for running the business. The purpose of the processed data is their easy interpretation and making the complete, qualitative and timely information that will support making the business decisions important to survival and growth of the company.

The responsibility of company's management, which makes all important decisions based on generated data, is enormous. It is especially important during the information system's development phase, and has even greater significance when making decisions about investment and initiating the projects of information system's development. All this will be considered in the continuance.

\section{MAKING THE BUSINESS DECISIONS}

Decisions which are result of business decision making, influence the greater or smaller proportion of employees, but sometimes even the complete working collective of an organisation. It is therefore extremely important to seriously and systematically approach to decision making. In time of prevailing informationcommunication technologies, business decisions' making couldn't be possible without them. In modern organisations, management relies on the qualitative and timely information. Information have become the equal organisational resource aside the traditional ones: human resources, machines, money, material and management. "Cognitive constraints refer to limitations in human capacities for saving and processing data. Namely, shortterm human memory cannot save all information needed to make decisions, since he doesn't process them fast enough, and memory and information processing are submissive to mistakes"[3]. Management therefore should have the right support when making decisions. Support can take shape of individual modelling techniques or usage of decision supporting systems. Individual modelling methods usually applied include linear programming, solving transportation problems, methods of economic evaluation, such as: method of return on investment period, method of internal rentability rate or net-value method.

\subsection{To buy or to develop own IS?}

Information system is a model of the business technology applied in certain organisation system [2]. Information system isn't used solely for preparation of strategic decisions, but it should also provide basics for making tactical and operative decisions so that the company, aggregated from numerous parts and functional units, could act as the business system [7]. Focus on costs' minimization and strong control is an essential factor in securing the competitiveness and strong position of a company.

The company itself invests its resources and energy in preparation and realisation of projects of implementing the new, upgraded or modified existing information system. According to the concise economic evaluation of the project, company's management has even a greater responsibility in making the investment decisions.

When making a decision, whether the business organisation will develop business system internally or it will buy the final product, it should bear in mind that purchase creates a long-term connection between the company and the producer/provider, so the future of business organisation will depend upon success of the chosen producer. The process of choosing the information system ends in concluding an agreement between company and producer/deliver/provider of the information system. The agreement should precisely 
define a product that producer should deliver, so the articles shouldn't be poorly defined or un-determent. Indirect costs of investments made in equipment, personnel's education and maintenance, as well the direct costs of organisation and personnel can emerge during the project as a consequence of insufficiently thorough problem analysis that causes additional investments. After the agreement has been concluded, any newly discovered need of a company, not covered by contract, will result in additional work and unplanned costs of the project, since the greatest proportion of business and risks belongs to the company.

Decision to develop own IS gives a company possibility to apply lean thinking principles in software development like presented in [6]. Building the comprehensive IS by the same company also enables the use of various information quality techniques and tools for optimized use of final product.

\subsection{ERP}

Concept ERP (Enterprise Resource Planning) describes planning of business resources. It primarily connotes to adjustment and usage of "final" software package, and subsequently the programme backup prepared according to the specifications of a certain user. ERP packages are imagined as adjustable to the needs of the concrete organisation and the existing software or information system of the same organisation [8]. Management should, by all means, consider the both possibilities, construction of own integrated information system, as well the procurement of the final product with eventual minimal corrections, according to the user company. The most quoted goal of introducing ERP system is integration of services and functions in business organisation and satisfying its needs by using the unique information system that provides insight in company's business. This is, without a doubt, one of the main goals of management of business organisations, when the usage of information communication technologies is in question [9].

Typical modules of the present ERP solutions are:

- Customer Relationship Management (CRM)

- Supply Chain Management (SCM)

- Procurement

- Product Lifecycle Management (PLM)

- Sales and Logistics

- Business Intelligence (BI)

- Financial Management

- Human Resource Management

- Project Management

- E-Commerce. [9]

Decision of development and investments in the project of ERP solutions will be made according to some of methods for evaluation and comparison of ERP systems. Since this is a complex system, its evaluation is also complicated. There is no generally accepted methodology of evaluation. The possible course of evaluation should include the following elements: analysis of market and application of ERP systems that should keep track of foreign and domestic providers of ERP programme backup, identification of users, the list of desirable sub-systems and business functions (ideal would be ERP system), the components of system that will be evaluated, desirable features that will be used in evaluation of individual component of ERP systems, and the procedure of evaluation and results' analysis. Within the present frames and offer, OpenSource ERP solution should definitely be regarded.

However, the main and sole purpose of ERP is to support business in order to make profit. There are certain doubts about possibilities of OpenSource ERP systems as backup to regular business. Some of the reasons OpenSource systems aren't appropriate to business making are:

- Relatively small number of users with only few of them having the capabilities and interest in active participation in future development.

- Huge volume of demands put in different industry sectors which makes the system complex since it tries to cover all required functionalities.

- In case of international organisations, a system should cover all specificities of business in a certain country, such as accounting, language and similar, which are relevant to the environment in which organisation acts.

- Companies which don't have own information departments, have every right to demand reliable development, backup and a possibility of education for usage and application of system, that's missing in the majority of the initiated ERP projects.

- Due to extremely constrained marketing capabilities, the OpenSource ERP systems have usually a low reputation among potential users.

- Documentation can be incomplete or outdated.

- Advantages for usage of OpenSource ERP systems in comparison to the commercial ones are as follows:

- Independence of development strategy and regulations set by commercial producer of the OpenSource ERP systems.

- Costs of OpenSource ERP systems have been reduced for the concession price, so those sources can be redirect to adjustment and development of OpenSource ERP system.

- Direct approach and right to changing the original code make OpenSource ERP systems more adjustable to their own needs.

- Developing process and the list of present mistakes are visible to the user, so it makes system more transparent.

- Functionalities developed for own needs can be divided with others and introduced into basic alternative, so the new functionalities emerge based upon real users' needs, and not upon opinion of marketing. There is a direct communication with the authors who develop the system.

- Users cannot be obligated to, during the strengthening or uploading the OpenSource ERP systems, monitor the strategy of producer and transfer to the new system [10].

Still, are then OpenSource ERP systems truly "open and free", and does the user depend on them as he does in the commercial systems?

Namely, certain producers of OpenSource ERP systems offer so-called community version and enterprise version. Usually these two versions differentiate only upon backup services that come with certain OpenSource 
ERP system, while the original code is identical in both cases. There is a possibility that backup is available only if enterprise version is in the executive form, so it doesn't have to be equally modelled as it is in case of community version.

Such differences in versions can become evident to the user only afterwards, when he already uses the system. Therefore it is necessary to check how much freedom OpenSource ERP system offers in the process of choosing [11].

All these are factors that every organisation and its management should evaluate if they want to apply OpenSource ERP system based on open code in their organisation.

\section{ECONOMIC EVALUATION OF INVESTMENTS MADE IN PROJECT AND ITS DEVELOPMENT}

The general concept of evaluation of investments made in a certain project refers to the set of activities which goal is to consider their feasibility and acceptability. Methods of evaluating the information system can be divided into economic, strategic, analytical and integrated. Strategic methods evaluate un-financial aspects such as competitive advantage and technical importance; analytical methods analyse the risks in business conducted by computer supported techniques, while economic methods use methods of return on investment period, method of the internal rentability rate and method of net present value.

Efficiency of project can be observed on the level of its effects that aren't immanent to the market, so its evaluation should be divided into the evaluation of market efficiency of project - the financial flow and evaluation of social-economic efficiency - the economic flow of the project [1].

In evaluation of the financial flow, a part of accumulation that will be created in the project is analysed since it will remain to the business organisation, while market prices reflect value of the invested costs and achieved effects. Economic flow includes the project effects immanent to all goals of the social-economic development, such as indirect effects in the project, and direct effects that will emerge within certain period of time outside the project. Evaluation of the investment project isn't made on the single basis. Changes in that aspect are the consequence of changes made in priorities in development goals. Investment decisions deeply rely on the economic flow of the project.

\subsection{Method of return on investment period}

Return on investment period is a method used for continuous monitoring of time and speed of returning the invested assets or time required for investment to return the invested money. It is defined as the sum of positive values of annual net incomes so to reduce sum of negative net incomes of project to zero, or to refund the investment made in the project. Net incomes represent difference between total incomes (project earnings, basic and active project funds) and project expenditures (investments in basic and active asset, material costs, gross payments, gain taxes). If net incomes in certain project year are positive, then the project asset has increased for the same year. Project asset has decreased when they are negative, and unchanged when they are equal to zero.

Evaluation criterion in this method is the longest planned return on investment period, which is being compared to the project return period, so there are three possible situations:

1. period of return < planned period of return: project is acceptable

2. period of return = planned period of return: project is partially acceptable

3. period of return $>$ planned period of return: project is unacceptable

If return on investment period is less or equal to the acceptable period of return, then the project is acceptable since the invested capital is being returned in period shorter than the planned. The length of planned return on investment period for project depends on numerous features of the business and development process. When defining planned return on investment period, it should be considered that this period isn't longer than the planned duration of the project. It can be shorter when technological progress is faster, since the equipment in this case becomes out of date relatively fast and it should be replaced more often.

Basic advantage of this method is that it puts emphasis on the fast return on investment so that it contributes to the higher liquidity of the project. The main disadvantage of this method is the excessive emphasis on the liquidity since it doesn't have to become the only goal of development strategy. If it is the only goal, then it neglects project effects that emerge after the return on investment period (except when return on investment period is the same as the projects duration). This method doesn't include capital costs since none costs of loan and own funds and discount techniques aren't included neither in the economic flow expenditures neither in budget of return on investment period. By considering advantages and disadvantages of this method it can be concluded that it should be used for short-period projects in situation when incomes and expenditures in the economic flow for starting years are higher than ones emerged later. It should also be used in situation when development process gives high importance to the faster return on investments. Since this method doesn't analyse time dimension of money, it should be used in combination with other methods.

\subsection{Net present value method}

Net present value indicates how much the project that is investment, influences the financial image of the company. Net present value is the sum of values indicating the annual net incomes reduced to their value in the starting year of project's lifecycle, or in the year 0 . Financial analysis calculates present value of incomes and outflows of the project's money. Between two projects, the one that has greater net present value is chosen. Net present value is determined according to the following expression: 


$$
N P V=\sum_{n=0}^{t} \frac{N P_{n}^{e}}{\left(1+\frac{p}{100}\right)^{n}}
$$

Where:

$N P V=$ Net present value of the project

$N P^{e}=$ Net incomes in the economic flow of the project

$p=$ Individual discount rate of the company

$n=$ Year in the project's lifecycle, with $n=0, \ldots, t$

or:

$$
\begin{aligned}
& N P V=\text { net_income } \\
& \text { o } \\
& \frac{\text { net_income }}{2}+\ldots+\frac{\text { net_income }_{1}}{r^{1}}+ \\
& r^{2}+\text { net_income }_{n} \\
& r^{n} \\
& \text { Where: }
\end{aligned}
$$

Discount rate should be estimated at the same level as the real interest rate approved on loans issued for financing the investments. If the project is financed by only one loan, then its interest rate is set as discount rate.

If the project doesn't use loans, discount rate should be estimated according to the real interest rate which banks apply to investment loans [5].

Criterion for evaluation used by this method refers to the net present value that can emerge in three versions:

$$
\begin{aligned}
& \text { NSV > 0: project is acceptable } \\
& \text { NSV }=0 \text { : project is partially acceptable } \\
& \text { NSV < 0: project is inacceptable }
\end{aligned}
$$

Project is acceptable if its net present value is positive or equal to zero, while it is inacceptable if its NPV is negative. This method has important positive features since it considers the whole project's lifecycle so it evaluates time preferences. The main disadvantage of this method is that it measures only the absolute effect the project has on the assets, not implying the size of investments needed to ensure net value, so discount values of the investments should be calculated.

Relative net present value which as relative indicator connects the net present value of the project and investment required for its realisation should be estimated according to:

$$
R N P V=\frac{\text { Project_NPV }}{\text { Investments_present_value }}
$$

RNPV connotes relative net present value of the project, indicating its investment's unit present value. The project is more acceptable when its relative net present value is higher. Method of net present value should be applied, with regard to its advantages and disadvantages, always during the evaluation process, especially in case of long-term projects.

However, if the financing includes several loans with different interest rates, then discount project rate should be calculated as weighted arithmetic mean of all interest rates according to the following equation:

$$
p=\frac{\sum_{m=1}^{M} K_{m} k_{m}^{r}}{\sum_{m=1}^{M} K_{m}}
$$

With:

$$
\begin{aligned}
& p=\text { Discount rate } \\
& K=\text { Loan value } \\
& k^{r}=\text { Real interest rate } \\
& m=\text { Loan in the financial structure, with } \mathrm{m}=1, \ldots, \mathrm{M}
\end{aligned}
$$

Discount rate can be even higher than the real interest rate approved for investment loans, which increases the pressure on the investments' efficiency. Evaluation of several projects should always apply the equal discount rate for all projects, so to ensure the precise comparison of the results.

\subsection{Method of the internal rentability rate}

Method of the internal rentability rate (IRR) measures the efficiency of project. It is defined as discount rate that levels the net present value of project to zero. Payable investment is the one by which the project's value is higher than the capital value, or where the net present value according to rentability rate amounts zero or a positive value. Between possible projects, the one with higher rentanbility rate will be chosen.

Internal rentability rate is calculated as follows:

$$
0=\sum_{n=0}^{t} \frac{N P_{n}^{e}}{\left(1+\frac{p}{100}\right)^{n}}
$$

with:

$$
\begin{aligned}
& N P_{n}^{e}=\text { Net incomes in the project's economic flow } \\
& p^{r}=\text { Internal rentability rate } \\
& n \quad=\text { Year in the project's lifecycle, with } \mathrm{n}=0, \ldots, \mathrm{t}
\end{aligned}
$$

Internal rentability rate can be calculated through iterative procedure as well. Iterative calculation uses different discount rates so to define the rate that brings net present value of project to zero. This method enables information about value of annual rate by which the project will decline accumulation defined as net income in the economic flow. Internal interest rate should always be considered as maximally acceptable interest rate for loans, regardless to usage of own capital in financing or using the loan. The financial obligations should also be repaid during the complete project's lifecycle. Internal rentability rate provides information of the average annual accumulation rate, but it doesn't specify the size of gain the project will realize during its lifecycle. Therefore, when evaluating the project, internal rentability rate should be combined with the net present value method, especially when it is difficult to determine the precise discount rate for reducing the figures on their net value [4].

\section{SENSITIVITY ANALYSIS}

The project investment relates to the future that isn't completely predictable, so planning the investments and 
making their economic evaluation should minimize mistakes in anticipations. Management which should make such a decision has a great responsibility. There are numerous causes of uncertainties in planning that could practically be divided into two basic groups. The first group is made of inner causes, among which the most important could be: capability of organisation and management, the chosen technology and location, productivity of work, capability of adjustment and alike. The second group is made of external uncertainties, placed in the investment project's environment, to which management cannot influence. These include changes in market's demand and offer, measures of economic policy, technological progress, economic trends etc. [1].

Though in reality inner and external causes of uncertainties act simultaneously, the level of that uncertainty can be reduced by timely and efficient planning, though it can never be completely eliminated.

Sensitivity analysis includes information derived from the complete project's lifecycle, and it aims at evaluating the acceptability of project when the values of crucial indicators of project's success are different than those planned in a prior analysis. The number of uncertainty factors varies from one project to another, with the most usual: volume of the market share, sell price of output, buying price of input, work and time norms, level of the capacity usage, length of project's cycle, the amount of investments, interest rates on loans, discount rate, inflation rate, excess of the planned deadlines in project's realisation.

The process of sensitivity analysis can be divided into the following phases:

- defining the critical elements of the project;

- defining the intervals of possible values of critical elements in the future;

- defining the probable values of the critical elements

- defining the project according to application of probable values of the critical elements

Specifying the minimal, probable and maximal values of critical elements should be made after the creation of the economic flow of the investment project.

\section{BEFORE THE CONCLUSION}

This paper applies the economic method for evaluation of management's role in development of information system. Still, other moments and factors which influence the applicative solutions as support to the IT system should be mentioned as well. They become crucial when business system chooses solutions of ERP type, or when compactness of information system deserves a special attention. Choice of qualitative ERP solution isn't simple, especially from the aspect of business system management. There are several reasons that should be considered in order to achieve economic effects in the acceptable way. However, if the aim is to extract specific factors and parameter, then time becomes a significant variable. Time is important out of several reasons. It is required to make a decision, to recognize the solution, to analyse the satisfaction of other clients who have already bought such solution and finally, certain amount of time will be required to introduce and stabilize ERP solutions.

Management can address several sources when trying to find a recommendation of proper choice of ERP solution. Within such circumstances usually consultant agencies are hired, which services must be settled, so they have to be carefully chosen. Management doesn't have to be acquainted with the professional information science terms, but it should be certain of the chosen ERP solution. IT employees, who are involved in the introduction of ERP solutions for a longer period of time, can contribute with their advices to making a final decision in the process of choosing the ERP solution, in sense of its volume, quality and mode of application.

Though usually not systematic or officially published, the Internet offers checked qualitative advices and instructions such as: who, when, how and what to consider when introducing the ERP solutions.

For instance, the authors [12] offer advices in form of the Six Best Practices for Selecting ERP Software. In the process, they have grouped basic instructions thorugh six main categories:

- Know your requirements.

- Make sure vendor competencies match your requirements.

- Check vendors' training and support resources.

- Treat your ERP project as a change-management project.

- Enlist the aid of consultants.

- Don't skimp when allocating resources.

[12] Represents a short sequence of advices which are not obliged, but still represent a summary of experiences of seven experts who have analysed the ERP solutions. The sequence itself indicated the economic, that is, financial severity of some advices.

A similar, though some broader list of advices and recommendations, has been given in [13]. The authors of this paper similarly group advices and recommendations that should be followed, if significant problems in ERP introduction are to be avoided. Their advices are summarized in ten points that are considered important. These are:

- Focus on the ERP solutions that target your company's requirements.

- Include a Software-as-a-Service solution in your assessments.

- Weigh each potential ERP vendor's strengths and weaknesses.

- Plan for the future.

- Assess your existing network.

- Consider each vendor's other business application offerings.

- Calculate the true total cost of ownership (TCO) of each ERP offering.

- Insist on a thorough demonstration of the ERP solution.

- Consider an ERP consultant.

- Buy only the modules you need. 
If the lists quoted in these two papers are compared, it becomes clear that among recommendation a detailed raster can be developed. Numerous similar advices can be browsed in the Internet.

By considering the experience and competence of persons who will be engaged as advisors or consultants, the management can accept or refuse the advices as the ones previously mentioned. Naturally, a certain attention should be given to the measure in which a business system is specific to its basic function or how specific are needs derived from specific function in the present moment, or how specific they'll become in the future development.

Finally, one extremely important fact should always bear in mind, and that would be the necessity of recognizing the ERP as paradigm that isn't immune to changes within field of ICT and techniques. ERP as paradigm is a way of approaching the organisation and managing the business supported by computer applications. This way the applied solution will become strictly connected to development of hardware and software, projecting and programming the computer applications. Each of these facts has a financial strength that can significantly vary, depending on the interrelations between specified factors. Therefore, the fourth advice from the second list: "Plan for the future" [13] actually implies that when buying ERP solution a client actually buys a "standardised product" which according to "number and design" has to satisfy "prêt-aporter" conditions and the ones that will emerge in the future. Which economic method will be used in evaluation and choice of ERP solutions doesn't solely depend upon management and its competence. The rightful decision also requires knowledge of the business system and its specific needs.

\section{CONCLUSION}

The more qualitative information is, the easier should be making the qualitative decision and undertaking the right action. Decision of developing the own business IS has a great potential of producing a tailor made, flexible solutions and qualitative informations. Economic gains of information backup to business decisions are reflected in cutting down all sorts of costs and waste. Other not so tangible aspect is the benefit of preventive actions that managers take using adequate informations.

Access to information and the possibility of quick preparations of new alternatives for analysis are advantage of using the modern technologies and their influence on the complete business system. In line with the approach to evaluation and decision making, company's management should develop a vision of using the potentials of information technology which settles the costs and success of implementation. This is especially important from the aspect of hidden costs which can't be assessed in advance such as: cost of users' education that includes adjusting the employees on the new work mode, integration and testing which depend on a need for connecting the newly implemented and already existing solutions and indeterminate long need for the consultants. Conversion of data is also commonly underestimated cost as it is data analysis when data of new business system should be combined with data of the external systems or resources. Unexpected decline of efficiency emerges when personnel aren't capable of executing the working tasks with help of implemented programme backup.

Investment in informatization of business processes, no matter how high still do not guarantee business effects. Focus on the business costs' minimization and their tight control is prevailing factor of competitiveness and company's strength since the highest cost emerges when bought information system isn't implemented or used due to unsatisfied users, which definitely presents a failed investment.

\section{REFERENCES}

[1] Bendeković, J. (1996). Planiranje investicijskih projekata, Ekonomski institut Zagreb, Zagreb

[2] Brumec, J. (2004). Sinopsis predavanja kolegija Informacijsko programsko inženjerstvo na Poslijediplomskom studiju Informacijske znanosti, Varaždin

[3] Čerić, V., Varga, M., Birolla, H.(1998) Poslovno računarstvo, Znak, Zagreb

[4] Davern, M.J.,Kauffman,R.J.(2000). Discovering Potential and Realizing value from IT investments, Journal of Managament Information System, Vol. 16, No.4, p.121-144

[5] Pogarčić, I. (2006). Sinopsis predavanja kolegija Ekonomika informacijskih sustava, Veleučilište u Rijeci, Rijeka

[6] Poppendieck, M., Poppendieck,T. (2007). Implementing Lean Software Develop-ment: from Concept to Cash. Addison-Wesley Professional, ISBN 0321437381

[7] Šehanović, J., Hutinski, Ž., Žugaj, M. (2002). Informatika za ekonomiste, Fakultet ekonomije i turizma "Dr. Mijo Mirković", Pula

[8] http://www.unibis.hr/ERP-HR.pdf (Accessed: 23.03.3009.)

[9] http://www.trend.hr/clanak.aspx?BrojID=38\&KatID=19\&ClanakI $\mathrm{D}=467$ (Accessed: 12.04.2009.)

[10] Stoj, G., "Pro und contra Open-Source-ERP", Computerwoche, 2005,http://www.computerwoche.de/knowledge_center/enterprise _resource_planning/554984/ (Accessed: 20.04.2009)

[11] Walker-Morgan, Dj., "The Open Source Enterprise Trap", The HOpen source, 2009, http://www.h-online.com/open/The-OpenSource-Enterprise-Trap-/features/112992 (Accessed : 20.04.2009)

[12] http://www.technologyevaluation.com/research/special-offers/6best-practices-for-selecting-erp-software-23696/(Accessed 20.03.2012)

[13] http://whitepapers.technologyevaluation.com/view_document/227 07/10-golden-rules-for-choosing-an-erp-system.html(Accessed 20.03.2012) 